\title{
Establishment of a patient-derived orthotopic osteosarcoma mouse model
}

\author{
Claudia Blattmann 1,3,6* Markus Thiemann ${ }^{1,3}$, Albrecht Stenzinger ${ }^{4}$, Eva K Roth ${ }^{1,3}$, Anne Dittmar ${ }^{2,4}$, Hendrik Witt ${ }^{1,5,6}$, \\ Burkhard Lehner ${ }^{7}$, Eva Renker ${ }^{7}$, Manfred Jugold ${ }^{8}$, Viktoria Eichwald ${ }^{8}$, Wilko Weichert ${ }^{4,6,9}$, Peter E Huber ${ }^{4}$ and \\ Andreas E Kulozik ${ }^{1,6,9}$
}

\begin{abstract}
Background: Osteosarcoma (OS) is the most common pediatric primary malignant bone tumor. As the prognosis for patients following standard treatment did not improve for almost three decades, functional preclinical models that closely reflect important clinical cancer characteristics are urgently needed to develop and evaluate new treatment strategies. The objective of this study was to establish an orthotopic xenotransplanted mouse model using patient-derived tumor tissue.

Methods: Fresh tumor tissue from an adolescent female patient with osteosarcoma after relapse was surgically xenografted into the right tibia of 6 immunodeficient BALB/c Nu/Nu mice as well as cultured into medium. Tumor growth was serially assessed by palpation and with magnetic resonance imaging (MRI). In parallel, a primary cell line of the same tumor was established. Histology and high-resolution array-based comparative genomic hybridization $(\mathrm{aCGH})$ were used to investigate both phenotypic and genotypic characteristics of different passages of human xenografts and the cell line compared to the tissue of origin.

Results: A primary OS cell line and a primary patient-derived orthotopic xenotranplanted mouse model were established. MRI analyses and histopathology demonstrated an identical architecture in the primary tumor and in the xenografts. Array-CGH analyses of the cell line and all xenografts showed highly comparable patterns of genomic progression. So far, three further primary patient-derived orthotopic xenotranplanted mouse models could be established.

Conclusion: We report the first orthotopic OS mouse model generated by transplantation of tumor fragments directly harvested from the patient. This model represents the morphologic and genomic identity of the primary tumor and provides a preclinical platform to evaluate new treatment strategies in OS.
\end{abstract}

Keywords: Osteosarcoma, Xenograft, Patient-derived, Primary cell line, Mouse model

\section{Background}

Osteosarcoma (OS) is the most common malignant pediatric bone tumor. Standard therapy comprises neoadjuvant chemotherapy, surgery and adjuvant chemotherapy with methotrexate, platin, alkylating agents and anthracyclines. While patients with localized and operable OS have a 5 year survival rate of approximately 60$70 \%$, outcome for patients with metastatic disease or non-resectable tumors is poor [1]. Over the past 30 years,

\footnotetext{
* Correspondence: c.blattmann@klinikum-stuttgart.de

'Department of Pediatric Oncology, Hematology and Immunology,

University of Heidelberg, Heidelberg, Germany

${ }^{3}$ Division of Radiooncology, German Cancer Research Center (DKFZ) Heidelberg, Germany

Full list of author information is available at the end of the article
}

survival rates did not improve. The development of new therapeutic approaches is urgently needed. Therefore, valid preclinical models reflecting human osteosarcomas are crucially required to facilitate rapid and effective development of novel therapies.

In principle, animal models can either be generated by inducing a tumor in a model organism or by xenografting human cancer cells or tissue into immunodeficient mice [2]. For the development of novel treatment strategies, human tumor xenografts are currently the most widely used models in a preclinical setting. They most resemble the human tumor despite the restrictions due to the immunodeficiency of the host organism. Genetically engineered mouse models (GEM) allow the study of 
effects of inhibitors against defined molecular targets. With these increasingly sophisticated models tissue specific molecular changes can be compared between individual cancers and tissues on the molecular level. Non-germline genetically engineered models allow the analysis of the impact of specific cancer genes without some of the limitations inherent in traditional GEM models. As mechanisms of transformation and oncogenesis differ between "mice and men" the generation of clinically relevant models using the mouse requires their humanization [3].

GEM have been instrumental in understanding the molecular mechanisms involved in tumor initiation. However, they have been less successful in replicating advanced cancer. Moreover, a particular genetic alteration frequently leads to different tumor types in human and mouse and to lower metastatic rates in GEM than in humans. These shortcomings limit the capacity of current GEM models to predict clinical response to a particular therapy. In contrast, orthotopic xenografts of human tumors, or tumor cell lines, implanted in SCID mice have high rate of reproducibility [4].

In OS, animal models are difficult to establish: osseous tissue is difficult to handle mechanically and technically challenging to be xenografted orthotopically. Previously, subcutaneous xenografts and orthotopic OS mouse models have been described using injection of cell suspensions and commercially available human cell lines [5-7]. Furthermore, there have been studies reporting genetically engineered models as well as models that employ tumor self-seeding following injection of tumor cells into the blood circulation of nude mice [8-10]. However, the applicability of these models is limited because genetically manipulated tumor cells are used to establish such models.

Hence, our goal was to establish a novel preclinical platform for rapid and effective development of new treatment strategies. Our new model system allows the generation of an orthotopic mouse model and a corresponding OS cell line using patient derived primary OS tissue.

MR imaging and histopathology, as well as array-CGH analyses were used to compare progression and human tumor. In addition, array-CGH analysis proved the genetic stability of this model, which will be used for preclinical developing of new treatment strategies in the future.

\section{Material and methods}

Patients and tumor samples

Tumor tissue samples were obtained from a patient with relapsed high-grade OS [11]. The study was approved by the ethics committee of the Medical Faculty of the
A Mouse $\mu C T$ whole body

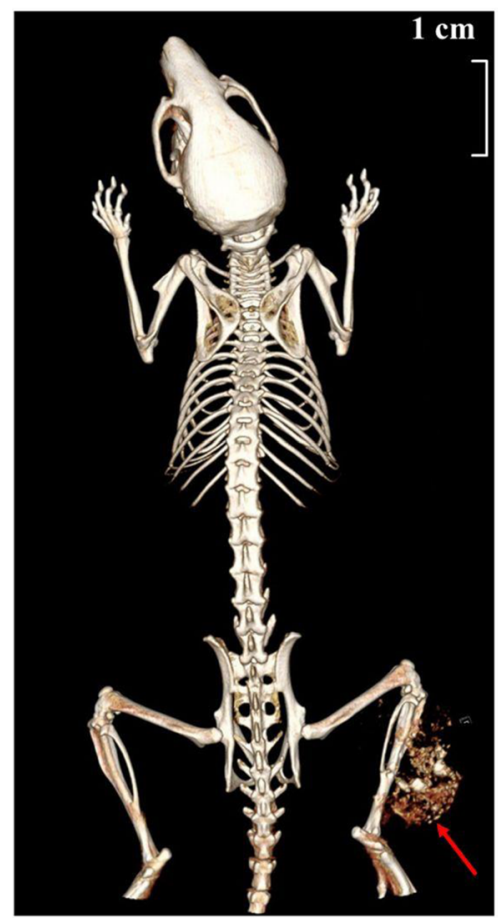

B
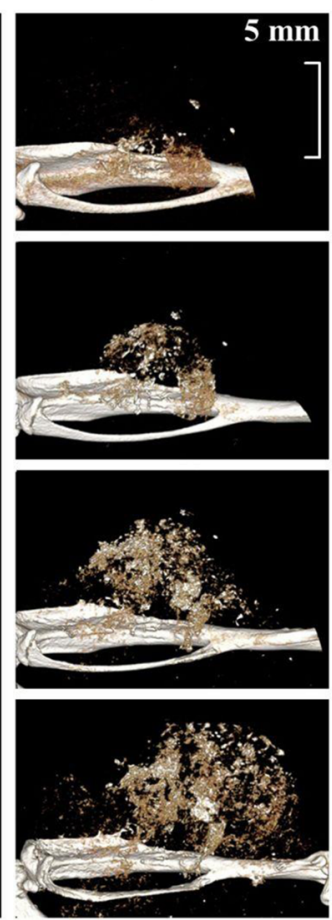

C T2w MRI
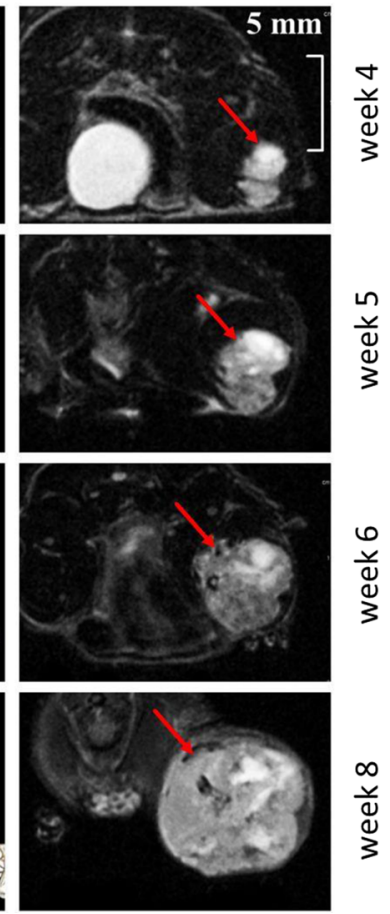

Figure 1 Representative MRI and $\mu \mathrm{CT}$ images of mouse xenografts 4 to 8 weeks after intratibial transplantation of patient-derived human OS tissue showing tibial tumor mass. A): $\mu \mathrm{CT}$ image of whole mouse body 8 weeks after tumor inoculation. B) and $\mathbf{C}$ ): $\mu \mathrm{CT}$ and T2 weighed (T2w) MRI images of tumor growth from week 4 to week 8 . Red arrows indicate tumor location. 
Table 1 Patient characteristics of tissue used for generation of patient-derived orthotopic mouse model

\begin{tabular}{|c|c|}
\hline Age \& Gender & 17 years, female \\
\hline Primary disease & diagnosed April 2008 \\
\hline - histopathology & osteoblastic osteosarcoma \\
\hline - Tumor location & right femur epiphysis, no metastases \\
\hline \multirow[t]{2}{*}{ - Treatment } & $\begin{array}{l}\text { according to EURAMOS } 106 / 2008 \text { - 11/2009, abortion of chemotherapy after the third postoperative cycle } \\
\text { by request of the patient and her parents }\end{array}$ \\
\hline & $\begin{array}{l}\text { Extraarticular tumor resection of the right femur (09.09.2008) and implantation of a Mutars-Endoprothesis } \\
\text { (regression grade II according to Salzer-Kuntschik) }\end{array}$ \\
\hline 1. Relapse & diagnosed 24 months after diagnose of primary disease \\
\hline - histopathology & - osteoblastic osteosarcoma \\
\hline - Location & - multifocal lesions in the right tibia, both lungs bilateral and the mediastinum \\
\hline - treatment & $\begin{array}{l}\text { - no further treatment because of the significant reduced general conditions and by request of the patient } \\
\text { and her parents }\end{array}$ \\
\hline Death of disease & 8 weeks after diagnose of relapse \\
\hline \multirow[t]{5}{*}{ Family history } & - Oldest child of four children \\
\hline & - Youngest brother died because of an embryonal rhabdomyosarcoma in 2000 \\
\hline & - Mother died because of a Mamma-Ca in 2006 \\
\hline & - Father, one younger sister and one younger brother are healthy \\
\hline & - Diagnostic concerning familiar tumor predisposition syndrome was declined \\
\hline
\end{tabular}

University of Heidelberg. After surgical resection and histopathological confirmation of the OS, the samples are stored in $\mathrm{NaCl} 0.9 \%$ on ice. A portion of the sample was xenotransplanted immediately (fraction 1 , see below). The remaining part of the samples was split into three further fractions (fraction 2 to 4 ) as follows: fraction 2 was put into DMEM medium, 10\% DMSO (Dimethylsulfoxide), 20\% FCS (fetal calf serum) and 1\% NEAA (Non Essential Amino Acid) under sterile conditions, was frozen stepwise to $-80^{\circ} \mathrm{C}$ and then transferred to liquid nitrogen. Fraction 3 was snap frozen and stored in liquid nitrogen. The fourth fraction was brought into cell culture in DMEM medium, 10\% FCS and 1\% NEAA (Non Essential Amino Acid) under sterile conditions and was cultured under standard conditions.

\section{Establishment of xenografts}

Fraction 1 of the human OS tissue was inserted into ten week old athymic BALB/c Nu/Nu mice (Charles River, Wilmington, Mass.) as follows:

Tumor samples were cut into $1 \times 1 \times 1 \mathrm{~mm}^{3}$ pieces. The right tibia of 6 mice was opened in the central (medial) part by drilling with a dental drill with a diameter of $0.5 \mathrm{~mm}$ to insert one tumor fragment in contact with the bone marrow. The anesthesia of mice was performed with isoflurane inhalation (1,5-3,5 Vol\% per liter oxygen). After, the surgical wound was sutured. The whole procedure took about $10 \mathrm{~min}$ per mouse. The percentage of success was $92 \%$. The mice were maintained under specific pathogen-free conditions, food and water were supplied ad libitum. Housing and all procedures involving the mice were performed according to the
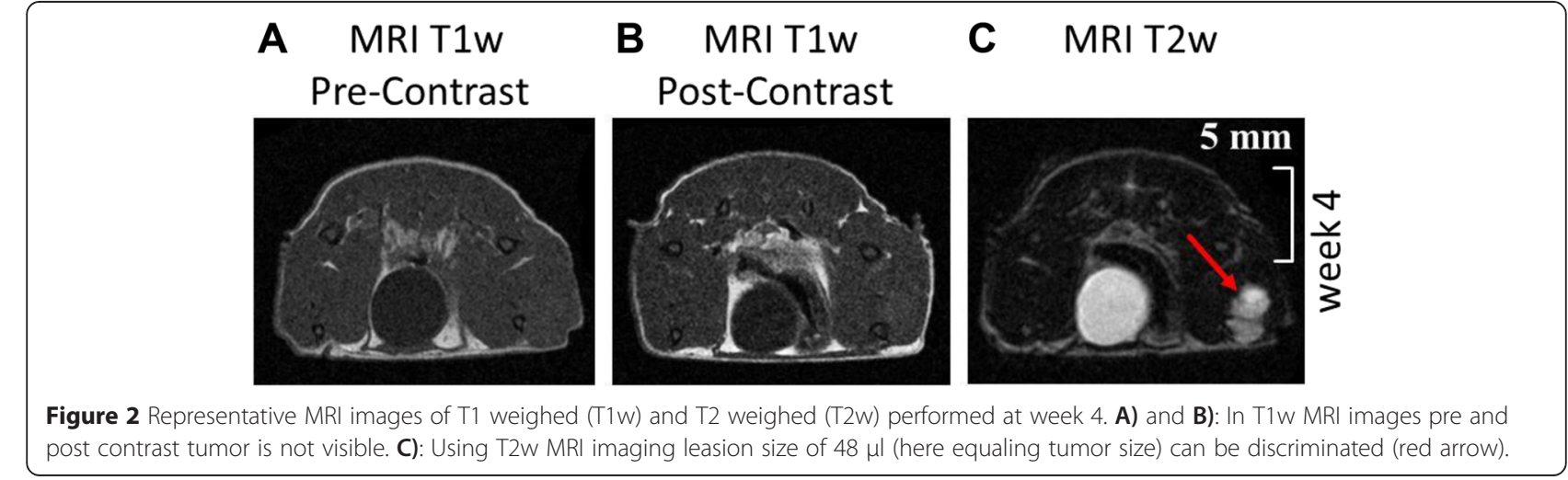

C $\quad \mathrm{MRIT} 2 \mathrm{w}$ 


\section{Human osteosarcoma fragment}

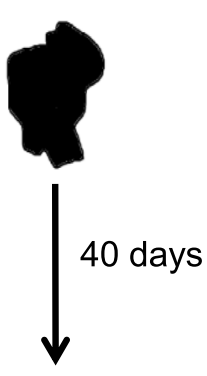

Mouse passage P1

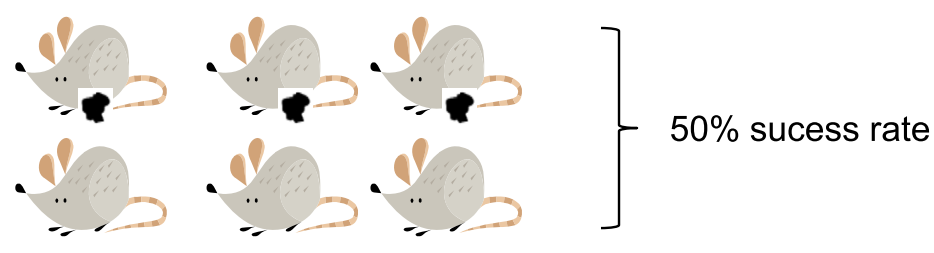

Re-passage of one tumor 30 days

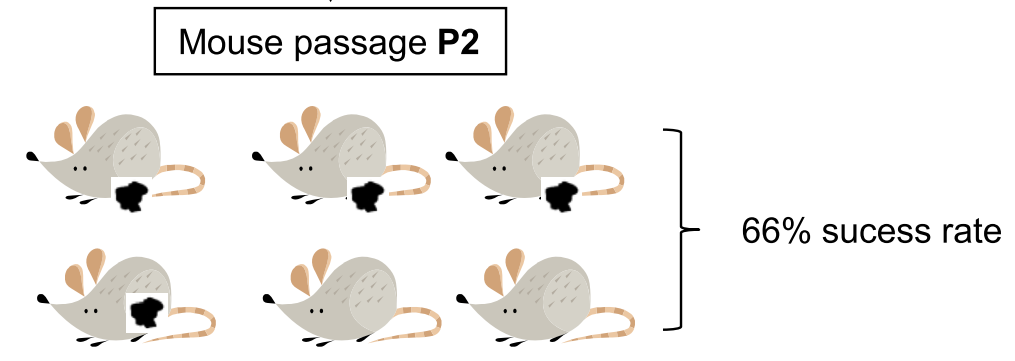

Re-passage of one tumor 20 days

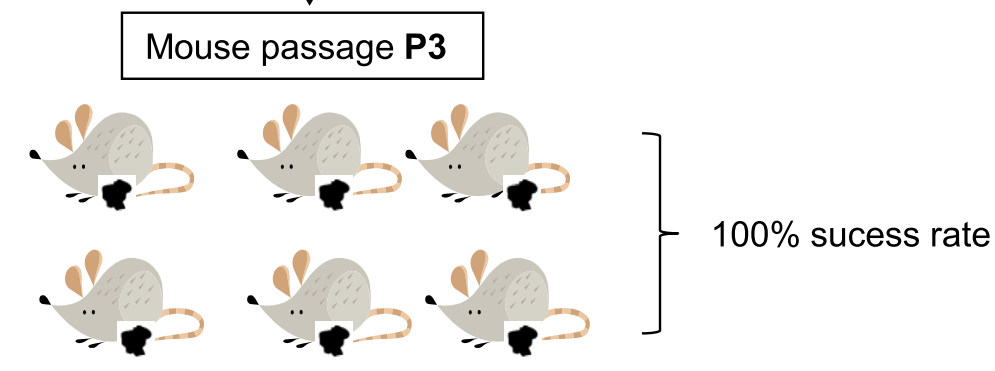

Figure 3 Establishment of patient-derived mouse model. Human OS tissue was transplanted into 6 mice with success rates of $50 \%$ in passage 1 (P1), 66\% in passage 2 (P2) and 100\% in passage 3 (P3). The number of days until tumor onset decreased from 40 (P1) to 30 (P2) to 20 days (P3). 
protocols approved by the German Cancer Research Center institutional animal care and use committee and by the local responsible government department (Regierungspräsidium Karlsruhe). Mice were observed daily for tumor growth by palpation and inspection.

MicroCT scans were acquired using an Inveon PET/ SPECT/CT system (Siemens Medical Solutions, Knoxville, TN, USA). A 12 minute and 30 seconds CT scan was performed with parameter settings: 360 rotation steps, tube voltage $50 \mathrm{kV}$, tube current $500 \mu \mathrm{A}$, binning 1 and exposure time $400 \mathrm{~ms}$. The pixel size was $0.0143 \times 0.0143 \times$ $0.0143 \mathrm{~mm}$. Image reconstruction was performed using the conventional Inveon Research Workplace software 4.0. The reconstruction filter was Shepp-Logan with a downsample factor of 2. MRI was performed using a small animal MRI scanner (Bruker Icon, 1 Tesla, Ettlingen, Germany). Because sufficient contrast for tumor discrimination could not be achieved using i.p. injection of Magnevist (Bayer Schering Pharma) at a concentration of $0.5 \mathrm{mmol} / \mathrm{ml}$ for contrast enhanced $\mathrm{T} 1 \mathrm{w}$ mri, tumor growth was visualized using $\mathrm{T} 2 \mathrm{w}$ images $(\mathrm{TE}=100 \mathrm{~ms}, \mathrm{TR}=2842 \mathrm{~ms}, \mathrm{FA}=180$, voxel size $=0.16 \times 0,16 \times 1 \mathrm{~mm}^{3}$, FOV $30 \times 30 \mathrm{~mm}$, matrix size $=192 \times 192$, averages $=4$ ). Lesion sizes were measured using T2 weighed (T2w) images and were found to match with tumor sizes obtained via $\mu \mathrm{CT}$ (Figure 1) and with weighed resected tumor tissues (data not shown). Measurements were performed by manual segmentation of the mass using Bruker ParaVision software. Mice were immobilized during the imaging procedures via Sevofluran inhalation narcosis at a dosage of $4 \%$ in air.

Human osteosarcoma fragment

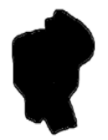

26 days

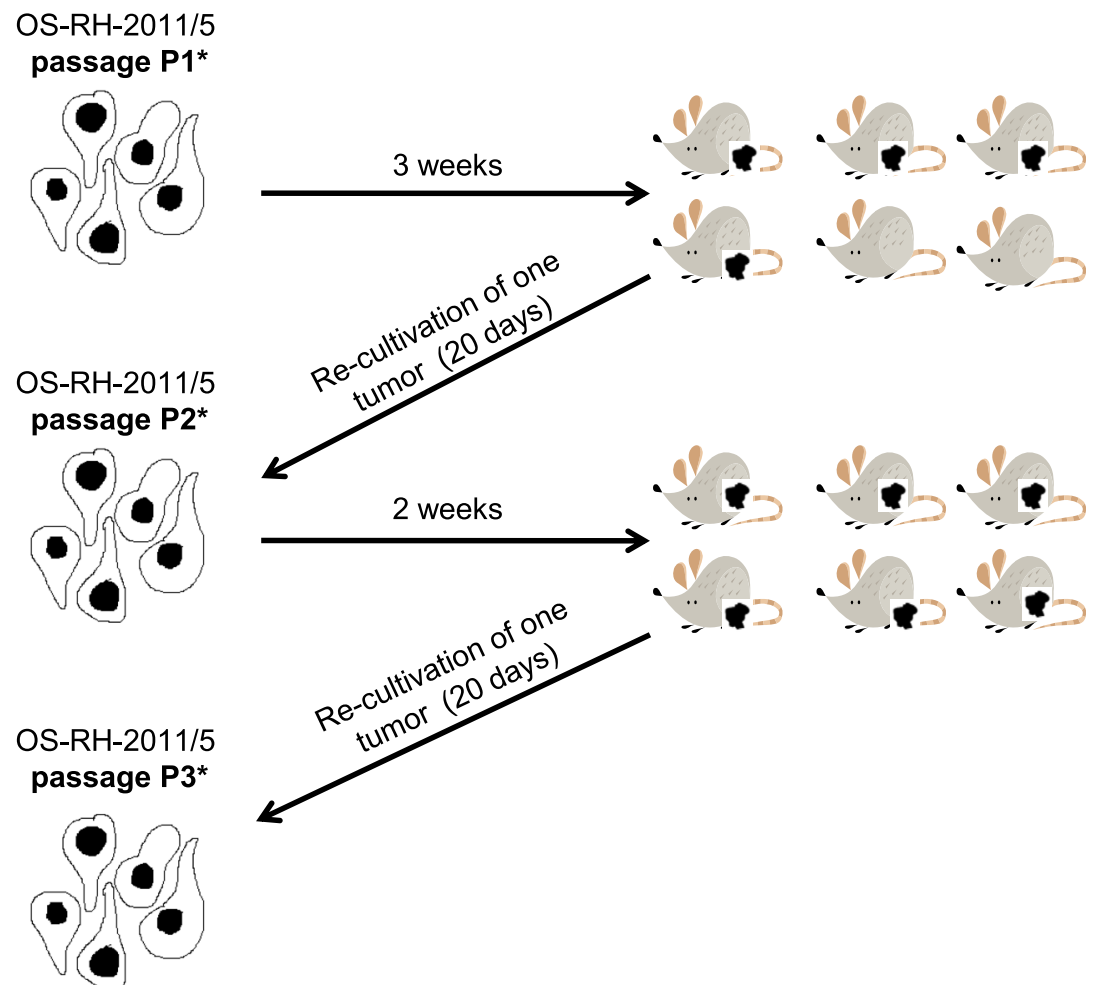

Figure 4 Establishment of the primary tumor cell line OS-RH-2011/5. The original tumor tissue was collected and directly cultivated into medium $\left(\mathrm{P} 1^{*}\right)$. After 26 days, cells were split and $3.75 \times 10^{6}$ cells were injected subcutaneously into the left flank of six athymic BALB/C Nu/Nu mice. After three weeks, four of six mice developed a tumor mass, which was removed when reaching a volume of $1.500 \mathrm{~mm}^{3}$. Tumor cells were then passaged in culture $\left(\mathrm{P2}^{*}\right)$, split after 20 days and again injected into the flank of six mice. After two weeks, all mice developed a tumor mass, which was removed and re-cultured (P3*) 


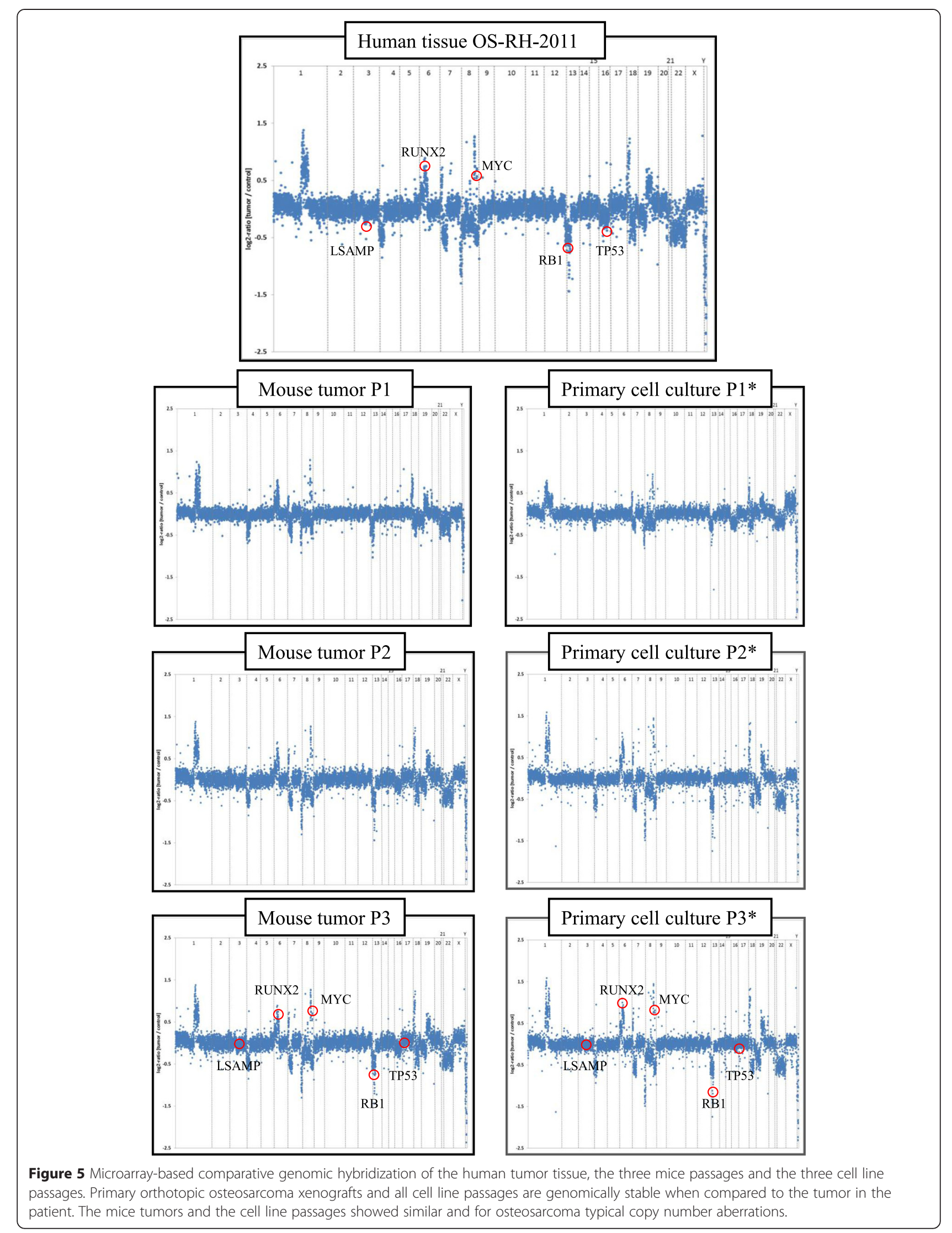


"Sufficient tumor growth" was defined as tumors in 3 of 6 mice attaining $1500 \mathrm{~mm}^{3}$. Each tumor was then removed and processed for the following analyses: (1) histopathological examination (2) array-based comparative genomic hybridization (aCGH) (see below), (3) orthotopic re-transplantation into 6 further mice, (4) recultivation in cell culture. One of the six tumors was cut into $1 \times 1 \times 1 \mathrm{~mm}^{3}$ fragments and transferred twice into 6 mice per passage (designated as passage P1 to P3). In the first passage (P1) three of six mice, in the second passage (P2) four of six mice and in the third passage (P3) six of six mice developed an orthotopic OS, which were frozen as outlined above for further analysis.

\section{Establishment of primary OS cell line}

The original tumor tissue was collected and directly cultivated into medium ( $\left.\mathrm{P}^{*}\right)$. After 26 days, cells were split and $3.75 \times 10^{6}$ cells were injected subcutaneously into the left flank of six athymic BALB/c Nu/Nu mice (Charles River, Wilmington, Mass.). After three weeks, four of six mice developed a tumor mass which was removed when reaching a volume of $1500 \mathrm{~mm}^{3}$. Tumor fragments were disaggregated and passaged again $(\mathrm{P} 2 *$ ), split after 20 days and injected into the flank of six further mice. After two weeks, all mice developed a tumor mass, which was removed, disaggregated and repassaged $(\mathrm{P} 3 \%)$. Each resected xenograft was first disaggregated into a cell line and then cells were re-injected. The cell line "passages" means sequentially passaged cells subcutaneously through the mouse and not just in culture. The third passage was used for further analysis. Cells were tested and proved to be free of mycoplasma, viral as well as cell contamination using in-house Multiplex cell Contamination testing (McCT) service [12]. Genetic stability of the cells was compared to the original human tumor sample at each passage by aCGH (see below).

\section{Microarray-based comparative genomic hybridization (a CGH)}

Genomic DNA from fresh frozen tissue was isolated using standard phenol-chloroform extraction. Genomic DNA from cultured cells was isolated using the Blood and Cell Culture Kit (Qiagen, Hilden, Germany) according to the manufacturer's instructions. Selection of genomic clones, isolation of BAC DNA, performance of degenerate oligonucleotide primer-PCR, and preparation of microarrays were performed as previously described [13]. Labeling, hybridization, and washing procedure were performed as reported previously [14]. Array- (or matrix-) $\mathrm{CGH}$ was carried out as described, gains were defined as copy number imbalances $\log 2$ ratio $>0,25$ and losses $\log 2$ ratio $<-0,25[15,16]$.

\section{Histopathology}

Histology was performed nine weeks after tumor implantation into the mice. $3 \mu \mathrm{m}$ thick whole tumor sections were cut from formalin-fixed, paraffin-embedded (FFPE) tissue blocks of all tumors. Sections were stained with hematoxylin-eosin (HE; Sigma-Aldrich, St Louis, USA). Histological comparisons were performed by two pathologists (AS, WW) using conventional HE-stainings as well as PAS and Masson Trichrom staining.

\section{Results}

\section{Establishment of a primary osteosarcoma orthotopic} mouse xenograft

Human OS tissue was collected from a 17 years old girl with an OS relapse in the right tibia with pulmonary and mediastinal metastases. Primary disease had been diagnosed two years previously with localized disease in the right distal femur. She received neo-adjuvant chemotherapy according to the EURAMOS 1 protocol [17]. The tumor was then completely resected and showed a grade 2 histological response (according to Salzer-Kuntschik;

Table 2 Frequent genetic aberrations in osteosarcoma

\begin{tabular}{|c|c|c|c|c|}
\hline $\begin{array}{l}\text { Gene locus (locus } \\
\text { name) }\end{array}$ & $\begin{array}{l}\text { Human tissue OS-RH- } \\
2011\end{array}$ & $\begin{array}{l}\text { Orthotopic mouse tumor } \\
\text { P3 }\end{array}$ & $\begin{array}{l}\text { Subcutaneous mouse tumor } \\
\text { P3 }\end{array}$ & $\begin{array}{l}\text { Primary cell } \\
\text { cultureP3* }\end{array}$ \\
\hline 1p22.3 (BCL10) & Gain / amplification & Gain / amplification & No variation & Gain / amplification \\
\hline 3q13.31 (LSAMP) & $\mathrm{LOH} / \mathrm{Del}$ & $\mathrm{LOH} / \mathrm{Del}$ & No variation & $\mathrm{LOH} / \mathrm{Del}$ \\
\hline 3p26.1 (SUMF1) & No variation & No variation & LOH / Del & No variation \\
\hline 6p21.1 (RUNX2) & Gain / amplification & Gain / amplification & No variation & Gain / amplification \\
\hline 7q31.33 (POT1) & Gain / amplification & Gain / amplification & No variation & Gain / amplification \\
\hline $8 q 24.21$ (Мyc) & Gain / amplification & Gain / amplification & Gain / amplification & Gain / amplification \\
\hline $13 q 14(\mathrm{RB} 1)$ & $\mathrm{LOH} / \mathrm{Del}$ & $\mathrm{LOH} /$ Del & $\mathrm{LOH} /$ Del & $\mathrm{LOH} /$ Del \\
\hline 17p13.1 (TP53) & Gain / amplification & Gain / amplification & No variation & Gain / amplification \\
\hline 17q25.1 (SLC25A19) & Gain / amplification & Gain / amplification & No variation & Gain / amplification \\
\hline 19q13 (GLTSCR1) & Gain / amplification & Gain / amplification & No variation & Gain / amplification \\
\hline
\end{tabular}

Loss of heterozygocity $(\mathrm{LOH})$ was defined as log2 ratio per clone $>-0.25$, Amplification was defined as log2 ratio per clone $>0.25$. 

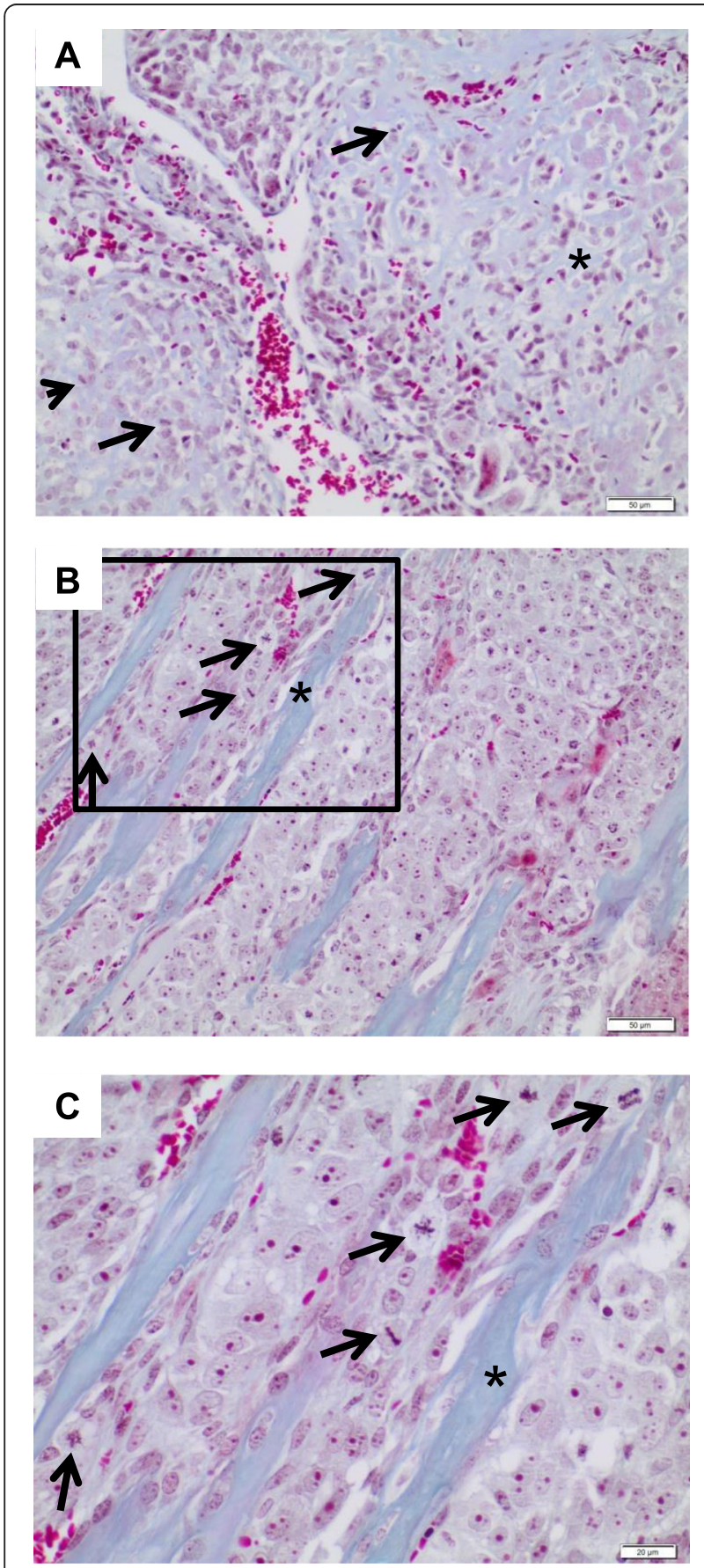

Figure 6 Representative histology of the tumors (Masson trichrom staining). Note the intimate association of neoplastic disorganized, fairly primitive trabeculae (bluish color) with the tumor cells (light red cytoplasm), which either present as lace-like pattern A) or as broad sheets $\mathbf{B})$. The arrows indicate mitosis, $\left(^{*}\right)$ indicates neoplastic osteoid. A): Relapsed primary osteosarcoma at the time of diagnosis $(\times 20), \mathbf{B})$ : corresponding patient-derived xenograft of mouse passage P3 (X20). As depicted here, the xenograft tumor closely resembles the relapsed primary including the production of neoplastic bone. Note the abundant mitotic tumor cells (arrows). C): Corresponding patientderived xenograft of mouse passage $\mathrm{P} 3$ at higher magnification (framed detail from $B ; \times 40$ ).
[18]). Subsequently, the patient received 3 courses of adjuvant chemotherapy. However, the protocol was discontinued by request of the patient and her family. The patient's mother died of breast cancer at an age of 43 years and the younger brother died of embryonal rhabdomyosarcoma of the chest wall at an age of 12 . The patient and her family did not consent to molecular diagnostic assessment to prove the presence of a familial tumor predisposition syndrome (Table 1).

Following biopsy of the relapsed tumor at the right tibia, tumor tissue was transplanted into the right tibia of 6 athymic BALB/c Nu/Nu mice as described in the methods section. After 40 days, 3/6 mice (Passage P1) developed a visible and detectable tumor mass in the MRI which was performed once a week (Figures 1 and 2 ). The tumors in the 3 mice were removed when the volume reached $1.500 \mathrm{~mm}^{3}$. Tumor tissue of one mouse was then re-transplanted immediately into the tibia of 6 further $\mathrm{BALB} / \mathrm{C} \mathrm{Nu} / \mathrm{Nu}$ mice (Passage 2). In this passage tumor growth was observed after 30 days in 4 of 6 mice. When the tumor volume reached $1.500 \mathrm{~mm}^{3}$, the tumors were removed. One of these tumors was retransplanted into 6 further mice (Passage 3), which all engrafted after 20 days (Figure 3). At each step, only one tumor was passaged.

The surrounding tissue of all tumors showed local infiltration into the soft tissue as well as the skin. However, until day 60 after tumor implantation into the mice, we could not find metastases anywhere.

\section{Establishment of a primary OS cell line OS-RH-2011/5}

Osteosarcoma tissue from our index patient was directly cultivated (Passage P1*; see methods section). After 26 days, culture was split and $3.75 \times 10^{6}$ cells were injected subcutaneously into the left flank of 6 mice.

After three weeks, four of six mice developed a tumor mass, which was removed when reaching a volume of $1.500 \mathrm{~mm}^{3}$. Tumor cells were then passaged in culture $(\mathrm{P} 2 *)$, split after 20 days and again injected into the flank of six mice. After two weeks, all mice developed a tumor mass, which was removed and re-cultured (P3*). Now, the third culture is used for further experiments e.g. investigation of new treatment strategies (Figure 4). The cells were monitored daily by microscopy. The cell morphology remained stable and very similar to the cells of origin (not shown).

\section{Genetic and histopathological characterization of the orthotopic patient-derived osteosarcoma xenograft and the primary osteosarcoma cell line}

We next analyzed the xenografts and the cell line passages by aCGH to detect genomic copy number variations (CNV) at a high resolution level. As expected for osteosarcoma, this analysis revealed a multitude of CNV. 
Importantly, all tumors and all cell line passages displayed a very similar genomic pattern, which closely resembled the genomic profile of the primary tumor tissue (Figure 5). Furthermore, we identified identical aberrations which are frequently observed in osteosarcoma (e.g. amplification of Myc and LOH in RB1) [19]. For a detailed overview see Table 2. These findings demonstrate a striking stability of genomic copy number variations in both the orthotopic xenografts as well as in the primary cell line. In addition, we compared the human tissue, the tumor of orthotopic xenografts and subcutaneous tumors. Here, our results showed different genomic patterns of the subcutaneous tumors compared to the human tumor and orthotopic tumors (Table 2). Gains of chromosomes 1, 7, 17 and 19 are not present within the subcutaneous OS model, in contrast an additional loss of regions of chromosome 3 was derived. However, these aberrations are possibly not driver events on OS pathogenesis, since these tumors arise with and without these alterations in different anatomical compartments.

Additionally, we investigated the morphology of the primary and our model system. To this end, mouse xenografts were examined by two pathologists. Compared to the clinical biopsies of the primary and relapsed tumors, which were both diagnosed as conventional high grade osteoblastic osteosarcoma, the xenografts displayed similar histological characteristics including mitotic figures and formation of neoplastic extracellular bone matrix into which tumor cells were incorporated (Figure 6).

\section{Discussion}

There is a disappointing lack of progress in the outcome of osteosarcoma patients over the last three decades despite well designed and large international prospective randomized clinical studies [20]. It is particularly notable that osteosarcoma, although occurring in about $5 \%$ of children and adolescents with cancer, is now the second most common cause of death in this age group [21]. Therefore, development of new treatment strategies requires systematic preclinical studies that can in turn be translated into the clinic. Existing model systems of osteosarcoma employ subcutaneous injections of immortalized established cell lines into the flank of mice. This model is fast, cheap, reproducible and easy to handle in experimental settings [7,22-28]. However, this model does not sufficiently reflect the human situation.

In 1997, Crnalic et al. reported a novel spontaneous metastasis model of human osteosarcoma developed using orthotopic transplantation of intact tumor cells into tibia of nude mice. Though, they used tumor tissue obtained from the 32nd serial passage of subcutaneously growing human osteosarcoma xenografts but did not perform any further genetic analysis to compare the tumor of origin to the mouse tumor.

In contrast, the important innovation we report here is a technique that enables orthotopic transplantation of human osteosarcoma tissue directly into the tibia of immunodeficient mice resulting in a reproducible and genetically representative patient xenograft model. So far, our model was established successfully using osteosarcoma tissue of three further patients (data not shown). However, the method requires specific technical skill and experience in animal models. But despite the significantly higher technical complexity and higher costs, such patient-derived orthotopic xenografts models can better recapitulate the biology of the human disease and thus facilitating the investigation of novel treatment strategies in a setting that more closely resembles the human primary tumor [29-33]. We are currently employing this novel tool to identify new compounds for the systemic treatment of osteosarcoma and for developing new strategies to achieve local control by heavy ion radiotherapy $[34,35]$.

\section{Conclusions}

In conclusion, we report the first orthotopic osteosarcoma mouse xenograft model, established by transplantation of tumor fragments directly harvested from the patient. This model has been shown to closely reflect the human disease on the level of morphology by MRI scanning and histopathology as well as on the genomic level as revealed by aCGH.

\section{Competing interests}

The authors declare that they have no competing interests.

\section{Authors' contributions}

BC conceived the study, wrote the application to the ethic committee, participated in the animal and cell line experiments and drafted the manuscript. TM developed and carried out the animal experiments. SA and WW carried out the histological examinations. REK and DA participated in the animal and cell line experiments. WH performed and analyzed aCGH experiments. LB and RE carried out the human tumor biopsies. JM and EV performed analyzed the MRI investigations. HPE participated in the animal experiments. KAE conceived of the study, participated in its design and coordination and helped to draft the manuscript. All authors read and approved the final manuscript.

\section{Acknowledgments}

This study was supported by a grant of the University of Heidelberg. Furthermore, we would like to thank Ludmilla Frick, Sylvia Trinh and Alexandra Tietz for their excellent technical assistance and the members of the Core Facility Kleintierbildgebung, DKFZ for the imaging diagnostics.

\section{Author details}

${ }^{1}$ Department of Pediatric Oncology, Hematology and Immunology, University of Heidelberg, Heidelberg, Germany. ${ }^{2}$ Department of Radiotherapy and Radiooncology, University of Heidelberg, Heidelberg, Germany. ${ }^{3}$ Division of Radiooncology, German Cancer Research Center (DKFZ), Heidelberg, Germany. ${ }^{4}$ Institute of Pathology, University of Heidelberg, Heidelberg, Germany. ${ }^{5}$ Division of Pediatric Neurooncology, German Cancer Research Center (DKFZ), Heidelberg, Germany. ${ }^{6}$ German Cancer Consortium (DKTK), Heidelberg, Germany. ${ }^{7}$ Department of Orthopedics, University of Heidelberg, Heidelberg, Germany. ${ }^{8}$ Core Facility, Small Animal Imaging Center, DKFZ, 
Heidelberg, Germany. ${ }^{9}$ National Center for Tumor Diseases (NCT), University of Heidelberg, Heidelberg, Germany.

Received: 24 November 2014 Accepted: 20 April 2015 Published online: 30 April 2015

\section{References}

1. Bielack SS, Kempf-Bielack B, Delling G, Exner BU, Flege S, Helmke K, et al. Prognostic factors in high-grade osteosarcoma of the extremities or trunk: an analysis of 1,702 patients treated on neoadjuvant cooperative osteosarcoma study group protocols. J Clin Oncol. 2002;20:776-90.

2. Langdon SP. Animal modeling of cancer pathology and studying tumor response to therapy. Curr Drug Targets. 2012;13(12):1535-47.

3. Berns A. Mouse models of cancer. Mol Oncol. 2013;7:143-5.

4. Hiroshima Y, Zhang Y, Zhang N, Uehara F, Maawy A, Murakami T, et al. Patient-derived Orthotopic Xenograft (PDOX) nude mouse model of soft-tissue sarcoma more closely mimics the patient behavior in contrast to the subcutaneous ectopic model. Anticancer Res. 2015;35(2):697-701.

5. Brennecke P, Arlt MJ, Campanile C, Husmann K, Gvozdenovic A, Apuzzo T, et al. CXCR4 antibody treatment suppresses metastatic spread to the lung of intratibial human osteosarcoma xenografts in mice. Clin Exp Metastasis. 2014;31(3):339-49.

6. Guijarro MV, Ghivizzani SC, Gibbs CP. Animal models in osteosarcoma. Front Oncol. 2014:4:182

7. Crnalic S, Häkansson I, Boquist L, Löfvenberg R, Brostrom LA. A novel spontaneous metastasis model of human osteosarcoma developed using orthotopic transplantation of intact tumor tissue into tibia of nude mice. Clin Exp Metastasis. 1997;15(2):164-72.

8. Zhang Y, Ma Q, Liu T, Ke S, Jiang K, Wen Y, et al. Tumor self-seeding by circulating tumor cells in nude mouse models of human osteosarcoma and a preliminary study of its mechanisms. J Cancer Res Clin Oncol. 2014;140(2):329-40.

9. Chan LH, Wang W, Yeung W, Deng Y, Yuan P, Mak KK. Hedgehog signaling induces osteosarcoma development through Yap1 and H19 overexpression. Oncogene. 2013;33(40):4857-66.

10. Brennecke P, Arlt MJ, Muff R, Campanile C, Gvozdenovic A, Husmann K, et al. Expression of the chemokine receptor CXCR7 in CXCR4-expressing human 143B osteosarcoma cells enhances lung metastasis of intratibial xenografts in SCID mice. PLoS One. 2013;8(9):e74045.

11. Fletcher CDM, Bridge J A, Hogendoorn P, Mertens F. WHO classification of tumours of soft tissue and bone. Volume 5. 4th ed. WHO Press.

12. Schmitt M, Pawlita M. High-throughput detection and multiplex identification of cell contaminations. Nucleic Acid Res. 2009;37:e119.

13. Solinas-Toldo S, Dürst M, Lichter P. Specific chromosomal imbalances in human papillomavirus-transfected cells during progression towardimmortality. Proc Natl Acad Sci U S A. 1997;94(8):3854-9.

14. Zielinski B, Gratias S, Toedt G, Mendrzyk F, Stange DE, Radlwimmer B, et al. Detection of chromosomal imbalances in retinoblastoma by matrix-based comparative genomic hybridization. Genes Chromosomes Cancer. 2005;43(3):294-301.

15. Solinas-Toldo S, Lampel S, Stilgenbauer S, Nickolenko J, Benner A, Döhner H, et al. Matrix-based comparative genomic hybridization: Biochips to screen for genomic imbalances. Genes, Chromosomes Cancer. 1997;20:399-407.

16. Pfister S, Remke M, Benner A, Mendrzyk F, Toedt G, Felsberg J, et al. Outcome prediction in pediatric medulloblastoma based on dna copynumber aberrations of chromosomes $6 q$ and $17 q$ and the myc and mycn loci. J Clin Oncol. 2009;27(10):1627-36.

17. Carrle D, Bielack SS. Current strategies of chemotherapy in osteosarcoma. Int Orthop. 2006;30(6):445-51.

18. Salzer-Kuntschik M, Brand G, Delling G. Bestimmung des morphologischen regressionsgrades nach chemotherapie bei malignen knochentumoren. Pathologie. 1983:4:135-41.

19. Man TK, Lu XY, Jaeweon K, Perlaky L, Harris CP, Shah S, et al. Genome-wide array comparative genomic hybridization analysis reveals distinct amplifications in osteosarcoma. BMC Cancer. 2004;4:45.

20. Luetke A, Meyers PA, Lewis I, Juergens H. Osteosarcoma treatment - where do we stand? A state of the art review. Cancer Treat Rev. 2014;40(4):523-32.

21. Ta HT, Dass CR, Choong PF, Dunstan DE. Osteosarcoma treatment: state of the art. Cancer Metastasis Rev. 2009;28(1-2):247-63.
22. Blattmann C, Thiemann M, Stenzinger A, Christmann A, Roth E, Ehemann V, et al. Radiosensitization by histone deacetylase inhibition in an osteosarcoma mouse model. Strahlenther Onkol. 2013;189(11):957-66.

23. Pignochino Y, Dell'Aglio C, Basiricò M, Capozzi F, Soster M, Marchiò S, et al. The Combination of Sorafenib and Everolimus Abrogates mTORC1 and mTORC2 upregulation in osteosarcoma preclinical models. Clin Cancer Res. 2013;19(8):2117-31.

24. Chaffee BK, Allen MJ. A clinically relevant mouse model of canine osteosarcoma with spontaneous metastasis. In Vivo. 2013;27(5):599-603.

25. Rao-Bindal K, Rao CK, Yu L, Kleinerman ES. Expression of c-FLIP in pulmonary metastases in osteosarcoma patients and human xenografts. Pediatr Blood Cancer. 2013;60(4):575-9.

26. Cole HA, Ohba T, Ichikawa J, Nyman JS, Cates JM, Haro H, et al. MicroComputed Tomography Derived Anisotropy Detects Tumor Provoked Deviations in Bone in an Orthotopic Osteosarcoma Murine Model. PLoS One. 2014;9(6):e97381.

27. Vormoor B, Knizia HK, Batey MA, Almeida G, Wilson I, Dildey P, et al. Development of a preclinical orthotopic xenograft model of ewing sarcoma and other human malignant bone disease using advanced in vivo imaging. PLoS One. 2014;9(1), e85128.

28. Folkvord S, Ree AH, Furre T, Halvorsen T, Flatmark K. Radiosensitization by SAHA in experimental colorectal carcinoma models - in vivo effects and relevance of histone acetylation status. Int J Radiat Oncol Biol Phys. 2009;74:546-52

29. Sicklick JK, Leonard SY, Babicky ML, Tang C-M, Mose ES, French RP, et al. Generation of orthotopic patient-derived xenografts from gatsrointestinal stromal tumor. J Transl Med. 2014;12:41.

30. Wong NC, Bhadri VA, Maksimovic J, Parkinson-Bates M, Ng J, Craig JM, et al. Stability of gene expression and epigenetic profiles highlights the utility of patient-derived paediatric acute lymphoblastic leukaemia xenografts for investigating molecular mechanisms of drug resistance. BMC Genomics. 2014;15:416.

31. Zhang H, Cohen AL, Krishnakumar S, Wapnir IL, Veeriah S, Deng G, et al. Patient-derived xenografts of triple-negative breast cancer reproduce molecular features of patient tumors and respond to MTOR inhibition. Breast Cancer Res. 2014;16(2):R36.

32. Wagner AJ. Patient-derived sarcoma xenografts for individual-patient selection of chemotherapy-ready for prime time? Cancer. 2014;120(13):1917-9.

33. Stebbing J, Paz K, Schwartz GK, Wexler LH, Maki R, Pollock RE, et al. Patientderived xenografts for individualized care in advanced sarcoma. Cancer. 2014;120(13):2006-15.

34. Blattmann C, Oertel S, Thiemann M, Weber K, Schmezer P, Zelezny O, et al. Suberoylanilide hydroxamic acid affects $\mathrm{YH} 2 \mathrm{AX}$ expression in osteosarcoma, atypical teratoid rhabdoid tumor and normal tissue cell lines after irradiation. Strahlenther Onkol. 2012;188(2):168-76.

35. Oertel S, Thiemann M, Richter K, Weber KJ, Huber PE, Perez RL, et al. Combination of suberoylanilide hydroxamic acid with heavy ion therapy shows promising effects in infantile sarcoma cell lines. Radiat Oncol. 2011;6:119.

\section{Submit your next manuscript to BioMed Central and take full advantage of:}

- Convenient online submission

- Thorough peer review

- No space constraints or color figure charges

- Immediate publication on acceptance

- Inclusion in PubMed, CAS, Scopus and Google Scholar

- Research which is freely available for redistribution 